appreciation" course, similar to "music appreciation" courses. It should not dwell excessively on conceptual basics, just as it would be a pity for a music appreciation course to limit itself to understanding chords without ever hearing a symphony. Similarly, elementary-school and high-school courses should also include the exciting results of modern astronomy in addition to providing astronomical basics.

Another analogy might be with teaching English. University professors of English (or, in non-English-speaking countries, of the respective dominant languages) are teachers of literature. They assume that grammar is known; they are sometimes willing to correct students' grammatical deficiencies, but those corrections are not their main job. These professors are to teach Shakespeare (or, in France, Victor Hugo) and the contemporary novel, rather than to teach punctuation. Even in schools during the lower grades, good English teachers teach about poetry and prose, and do not limit themselves to grammar. Analogously, we astronomers must bring our students to see the wonders of the universe in the view of our latest understandings as demonstrated by the glories of contemporary research.

\title{
Textbook Panel Presentation - IAU Colloquium 105
}

\author{
R. Robert Robbins, \\ Department of Astronomy, University of Texas, Austin, Texas 78712, U.S.A.
}

You might be somewhat surprised by the presentations [as delivered] so far, in that there has been relatively little discussion of pedagogical matters (e.g., what should be the content of a text and what should be its order and manner of presentation). It seems that rather personal factors are in the foreground of everyone's thinking. But I think that is probably inevitable, because the process of writing a textbook is not only a huge undertaking that comes to dominate the life of the author, but it is also an endeavor that places the author directly at the interface between the idealistic world of education and the very practical world of economics as dictated by the realities of the publishing markets. In addition, a textbook has a strong effect on an astronomy class. It has been suggested that an important reason why so many educational research studies fail to come to a definite conclusion is that the textbook is such a dominant influence that it swamps all the other factors!

We have already seen that much of the astronomy teaching in the United States is in courses for non-science majors. These courses generate huge enrollments; at my institution, we teach some 7000 students per year (about 20,000 credit hours). It is these enrollments that make it possible for commercial publishers to make a profit on a textbook, because every student is expected to buy a copy of the book. And of course we see the evidence of this - a great proliferation of non-mathematical texts for non-science majors, in English.

Where it is not profitable to publish a book, the books do not appear. Note the shortage of books for astronomy majors, even in English. The market is just too 
small. Technical symposia do make their way into print, but the prices of the volumes are often incredible (in some cases up to $\$ 1000$ !). And in the European educational system (and in countries following a similar pattern), enrollments are smaller and students are not expected to buy a text. In these circumstances, publishing is often not economically feasible.

One solution is perhaps to create larger enrollments (for example, by teaching classes for non-science students, or requiring the books). But this requires large changes in educational systems, which by their very size are conservative and hard to change. However, if some markets were to be created for commercial publishers, they would make some profits and then perhaps be more willing to produce some of the advanced volumes that are needed, perhaps even at a loss. Or be more willing to permit translations into local languages, perhaps at no profit to themselves.

If a way to produce some commercial profits is not found, then books will only appear if they are subsidized in some way, and this is traditionally a slower and less-dependable route. I have proposed that Commission 46 of the IAU attempt to locate some modest funding to support prospective textbook writers in developing countries to produce texts in their local languages. I feel that sponsoring a semester or a year's sabbatical for a local author would be only a modest expense and would bring a substantial educational return.

From a personal point of view: if you are considering writing a text book, you should realize that (1) it takes a very long time - much, much longer than any estimate you might project and (2) the market is actually very competitive and finite, with a number of good books already on the market. As an indicator, I have just finished compiling a comprehensive listing of new astronomy books in English for IAU Commission 46. Between January 1, 1985, and December 31, 1987, new astronomy books of all kinds in English appeared at the rate of one every 28 hours!

As a further practical consideration, there is a serious war going on between the publishers and the book stores in the U.S. market over used textbooks. Bookstores can make more money reselling used books than they can selling the new texts. Such sales generate no income for authors or publishers. The publishers retaliate by having their authors put out a new edition every year and a half, which wastes the author's time and often has no sound pedagogical justification.

The idealistic side of you probably wants to rebel against having to worry about all of these economic considerations, but you cannot. Because if you are going to actually put in all of that work to write a textbook, then in order to have the continuing benefit of the text you have written - it must survive in the marketplace. And this means that there is no way to avoid interfacing with the real world of economics. So while you will hear various horror stories of author-publisher interactions, realize that things can go wrong in any endeavor and prepare your mind for all possibilities. Your best protection is to know your editors well, and, as best you can, evaluate them as people and as professionals and hope for the best.

You will certainly not get rich by writing a textbook, so I would advise you to undertake this endeavor only if you have a very important academic or personal reason for doing so. For example, I wrote my book because of my personal dissat- 
isfaction with the existing texts on the market: 95 per cent of the students across the country were taking astronomy without having any contact with astronomical observations, the sky, or the measurement-inference process that is at the heart of science. I had no success in trying to graft one of the existing "lab" manuals onto my lectures, so I ended up writing a book in which some observational activities were integrated into the text itself where appropriate. Now my students can acquire some of the knowledge in the syllabus by astronomical investigations - the active discovery process advocated by Piaget and other cognition researchers, as opposed to passive lecture experiences. Not all of the material can be taught by discovery methods, but I am very happy with that portion that can be structured in this way and the student response has been very favorable.

\section{Textbooks: A Survey}

After the panel and open discussions on textbooks, John Stull and Scott Weaver of Alfred University, Alfred, New York 14802, kindly prepared a questionnaire on textbooks, and collected and analyzed the results. [The Organizing Committees are grateful to them for undertaking this survey.] The following is a summary of their report.

Responses were received from 23 people from 14 countries. Although this limited response precludes meaningful generalization, it generally supports the views expressed in the panel discussion. U.S. texts, with their frequent editions, up-to-theminute information and many illustrations (frequently in color) are not only inconvenient for non-English speakers, but also out of reach in countries where dollars are scarce. They may also have an annoying amount of cultural and geographical bias. The lack of locally-written texts adds to this difficulty. Many non-U.S. respondents indicated that they write and distribute lecture notes; these notes may eventually be the basis for locally-written texts. The main problems of textbooks may well have been identified at this Colloquium, but were by no means solved. Further thought and effort seem justified.

\section{Discussion}

H.F. Haupt: Comment on "Textbooks" from a non-American in a non-English speaking country:

- at the university in Austria, we teach only science-majors

- we mention a few (a dozen) textbooks (both in German and in English) that students can look into at our libraries; but normally students will not buy these 